\title{
Growth hormone release during sleep in growth retarded children
}

\author{
C. J. EASTMAN and L. LAZARUS \\ From The Garvan Institute of Medical Research, St. Vincent's Hospital, Sydney, Australia
}

\begin{abstract}
Eastman, C. J., and Lazarus, L. (1973). Archives of Disease in Childhood, 48, 502. Growth hormone release during sleep in growth retarded children. Plasma growth hormone ( $\mathrm{HGH})$ concentration was measured at frequent intervals during EEG-monitored nocturnal sleep in 12 children of short stature. Sleep-related HGH peaks were compared with peak HGH responses to arginine infusion and to insulin-induced hypoglycaemia. Peak plasma HGH levels during sleep ranged from $26 \cdot 4$ to $36 \cdot 8 \mu \mathrm{U} / \mathrm{ml}$ in 5 children with constitutional short stature, and from $14 \cdot 8$ to $28 \cdot 4 \mu \mathrm{U} / \mathrm{ml}$ in 4 children with chronic asthma. 3 hypopituitary children failed to show rises in plasma HGH levels despite EEG-adjudged normal sleep patterns. In the children who were not growth hormone deficient, maximum increases in plasma HGH concentration occurred from 30 to 90 minutes after the onset of sleep, and were associated with slow-wave sleep patterns on the EEG.

HGH responses to the pharmacological stimuli were comparable with the sleeprelated HGH peaks in 9 of the 12 patients studied. In 2 patients with constitutional short stature, blunted HGH responses to arginine were associated with normal rise in plasma HGH during sleep and during insulin-induced hypoglycaemia. 1 child with impaired growth after operation for a craniopharyngioma exhibited a normal $\mathrm{HGH}$ response to arginine $(20 \cdot 4 \mu \mathrm{U} / \mathrm{ml})$, a subnormal $\mathrm{HGH}$ response to insulin $(7 \cdot 4 \mu \mathrm{U} / \mathrm{ml})$, and a peak plasma $\mathrm{HGH}$ of $4 \mu \mathrm{U} / \mathrm{ml}$ during sleep. Subsequent treatment with exogenous $\mathrm{HGH}$ produced a rapid acceleration in height velocity suggesting that impaired growth was due to growth hormone deficiency.

These studies are in accord with the suggestion that sleep-induced HGH release is an index of physiological HGH secretion, and that measurement of $\mathrm{HGH}$ release during sleep may prove a valuable tool in the detection of growth hormone deficiency in children of short stature.
\end{abstract}

Spontaneous release of human growth hormone (HGH) during sleep is closely related to the state of slow-wave sleep, as determined by electroencephalographic (EEG) criteria (Takahashi, Kipnis, and Daughaday, 1968; Honda et al., 1969; Parker et al., 1969; Sassin et al., 1969). It appears that sleepinduced $\mathrm{HGH}$ release is a manifestation of a stable neuroendocrine rhythm, which is repetitive from night to night and independent of acute changes in the availability of metabolic substrate (Takahashi et al., 1968; Vanderlaan et al., 1970). The usefulness of this phenomenon as a diagnostic measure of physiological HGH release in adults has been emphasized (Mace et al., 1970; Eastman and Lazarus, 1971); however, its clinical use in children has not been fully explored.

Received 22 November 1972.
The aims of this study were to determine the usefulness of sleep-related $\mathrm{HGH}$ release as a physiological test of pituitary function in children of short stature, and to compare the response with the HGH responses to provocative, pharmacological stimuli. Our results indicated that prepubertal children exhibit significant rises in plasma HGH during sleep and that measurement of sleeprelated HGH release is a good index of physiological HGH secretion.

\section{Materials and methods}

Patients. The clinical details of the 12 patients studied are shown in Table I. All the children were prepubescent and were referred for investigation of short stature. The diagnosis of constitutional short stature was made in 5 children on the basis of history, clinical signs, the results of pituitary function studies, and subsequent growth and development. The 4 
TABLE I

Clinical details of children studied

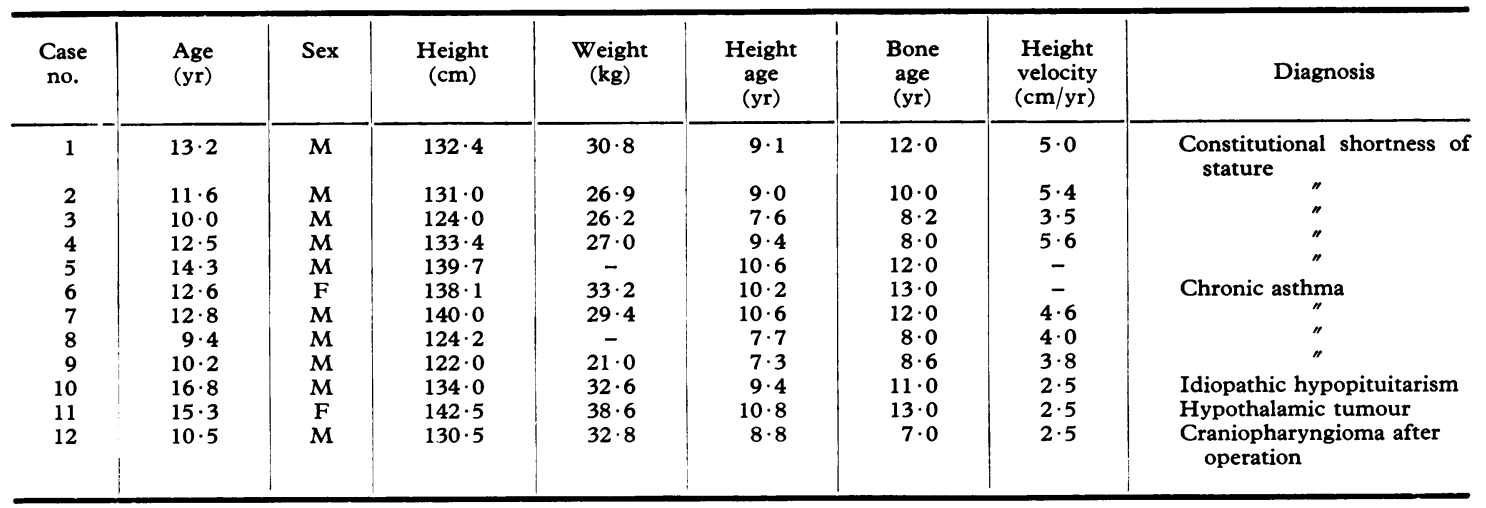

asthmatic children were well controlled symptomatically at the time of investigation and had not received any corticosteroids over the previous 6 months. One of the 3 hypopituitary children had idiopathic hypopituitarism from infancy. The other 2 hypopituitary children had organic hypopituitarism due to intracranial space-occupying lesions. Case 11 had an inoperable tumour of the hypothalamus and Case 12 had been operated on successfully for removal of a craniopharyngioma 2 years before this investigation.

Detailed investigations of pituitary function were performed on each patient included in this study. HGH secretion was assessed by measurement of sleepinduced HGH release and by the plasma HGH response to arginine infusion and insulin-induced hypoglycaemia.

Sleep studies. On the day of the sleep study the children were given their evening meal between 4.30 and $6 \mathrm{p} . \mathrm{m}$. and then were confined to bed until completion of the test the following morning. Normal sleeping conditions were simulated as closely as possible, according to the usual habits of the individual. At least 2 hours before the onset of sleep, an indwelling polyethylene catheter was inserted into an antecubital vein and firmly attached to the forearm with tape. The opening of the catheter was plugged with a disposable cap, which was easily removed for the withdrawal of blood samples during the night. Patency of the catheter was maintained by the injection of heparinized saline (10 IU/2.5 ml) after the withdrawal of each blood sample. Venous blood for the estimation of plasma HGH, plasma cortisol, and blood glucose was withdrawn before the onset of sleep and thereafter at frequent intervals determined mainly by the patient's EEG sleep stage.

EEG and EOG (electro-oculogram) traces were recorded in all patients, either on a conventional 16 channel electroencephalogram or on a portable continuous oscilloscopic monitor with an attached paper print out. Sleep was scored and classified according to established criteria (Rechtschaffen and Kales, 1968). Satisfactory sleep patterns were recorded in all patients included in this study. Once they were acquainted with the details of the test most of the children had little difficulty in going to sleep and did not appear to be stressed or inconvenienced by the procedure.

Sequential arginine infusion and insulin-induced hypoglycaemia stimulation tests were performed on each patient on completion of the sleep study (Penny, Blizzard, and Davis, 1969). Arginine hydrochloride in a dose of $0.5 \mathrm{~g} / \mathrm{kg}$ was infused as a $10 \% \mathrm{w} / \mathrm{v}$ solution in physiological saline over a period of 30 minutes. Insulin was administered intravenously in a dose of 0.075 to 0.1 units $/ \mathrm{kg} 75$ to 90 minutes after starting the arginine infusion. Venous blood for estimation of plasma HGH, plasma cortisol, and blood glucose was withdrawn at 15-minute intervals over a period of $2 \frac{1}{2}$ to 3 hours.

Laboratory methods. Plasma HGH was measured by a modification of the double antibody radioimmunoassay of Pennisi (1968). The results are reported in $\mu \mathrm{U} / \mathrm{ml}$ of the WHO IRP standard for immunoassay. To minimize interassay variation, all blood samples taken from an individual patient during the various tests were included within a single assay. Quality control was monitored according to the method of Rodbard et al. (1968). The sensitivity of this assay was $1 \cdot 0 \mu \mathrm{U} / \mathrm{ml}$ and the precision, defined as $95 \%$ confidence limits for replicate estimations of plasma $\mathrm{HGH}$ at $5 \cdot 0,10 \cdot 0,20 \cdot 0$, and $40.0 \mu \mathrm{U} / \mathrm{ml}$ in a representative assay, was \pm 0.8 , $\pm 1 \cdot 2, \pm 2 \cdot 0$, and $\pm 6 \cdot 0 \mu \mathrm{U} / \mathrm{ml}$, respectively. Between assay variability was assessed by including quality control sera in each assay. The between assay precision at plasma $\mathrm{HGH}$ levels of $4 \cdot 0,8 \cdot 0$, and $20 \cdot 0 \mu \mathrm{U} / \mathrm{ml}$ was $\pm 0.6, \pm 2 \cdot 0$, and $\pm 3.0 \mu \mathrm{U} / \mathrm{ml}$, respectively. Blood glucose was measured by the autoanalyser Technicon ferricyanide method of Hoffman (1937). 


\section{Results}

Plasma HGH during sleep. The peak plasma HGH levels recorded in each patient during sleep and the temporal relation of the peak with the onset of sleep are shown in Table II. The 5 children

TABLE II

Sleep-related $H G H$ responses

\begin{tabular}{c|c|c|c}
\hline Case no. & $\begin{array}{c}\text { Presleep } \\
\text { plasma HGH } \\
(\mu \mathrm{U} / \mathrm{ml})\end{array}$ & $\begin{array}{c}\text { Peak plasma } \\
\text { HGH during } \\
\text { sleep }(\mu \mathrm{U} / \mathrm{ml})\end{array}$ & $\begin{array}{c}\text { Time from } \\
\text { onset of } \\
\text { sleep }(\mathrm{min})\end{array}$ \\
\hline 1 & $4 \cdot 0$ & $36 \cdot 8$ & 45 \\
2 & $2 \cdot 0$ & $26 \cdot 4$ & 30 \\
3 & $1 \cdot 0$ & $32 \cdot 2$ & 50 \\
4 & $2 \cdot 0$ & $27 \cdot 0$ & 65 \\
5 & $11 \cdot 2$ & $28 \cdot 8$ & 85 \\
6 & $2 \cdot 4$ & $14 \cdot 8$ & 90 \\
7 & $3 \cdot 2$ & $25 \cdot 2$ & 65 \\
8 & $1 \cdot 0$ & $18 \cdot 2$ & 65 \\
9 & $1 \cdot 6$ & $28 \cdot 4$ & - \\
10 & $1 \cdot 0$ & $1 \cdot 0$ & 60 \\
11 & $1 \cdot 0$ & $3 \cdot 2$ & 45 \\
12 & $1 \cdot 6$ & $4 \cdot 0$ & \\
\hline
\end{tabular}

with constitutional short stature and the 4 asthmatic children had significant increases in plasma HGH levels during sleep, with peak levels occurring in association with slow-wave (stages 3 and 4) sleep (Fig. 1). The peak plasma HGH levels ranged from 26.4 to $36.8 \mu \mathrm{U} / \mathrm{ml}$ in the children with constitutional short stature, and from 14.8 to $28.4 \mu \mathrm{U} / \mathrm{ml}$ in the asthmatic children. 1 child (Case 5) had two large peaks of HGH during the night, occurring at 85 minutes $(24 \cdot 0 \mu \mathrm{U} / \mathrm{ml})$ and 360 minutes $(28 \cdot 8 \mu \mathrm{U} / \mathrm{ml})$ after the onset of sleep. The mean peak plasma HGH level in the 9 children who were not growth hormone deficient was $26 \cdot 4 \pm 2 \cdot 2 \mu \mathrm{U} / \mathrm{ml}$. The 3 hypopituitary children failed to show a normal rise in plasma HGH during sleep. HGH levels were below detectable limits throughout the night in 1 child (Case 10) and rose to 3.2 and $4.0 \mu \mathrm{U} / \mathrm{ml}$ in the other 2 during EEGadjudged normal sleep.

Plasma HGH responses to provocative stimulation tests. Plasma HGH responses to sequential arginine infusion and insulin-induced hypoglycaemia are compared with the sleep responses in Table III. Though the mean peak plasma HGH responses to sleep $(26 \cdot 4 \pm 2 \cdot 2 \mu \mathrm{U} / \mathrm{ml})$, arginine $(22 \cdot 8 \pm 3 \cdot 8 \mu \mathrm{U} / \mathrm{ml})$, and insulin-induced hypoglycaemia $(23 \cdot 6 \pm 3 \cdot 8 \mu \mathrm{U} / \mathrm{ml})$ are comparable in the children who were not growth hormone deficient, 2 patients (Cases 3 and 4) who exhibited blunted HGH responses to arginine responded well to both sleep and insulin-induced hypoglycaemia.
Two of the 3 hypopituitary children failed to respond normally to both arginine infusion and to insulin-induced hypoglycaemia stimulation. Plasma HGH levels during sleep were consistent with the
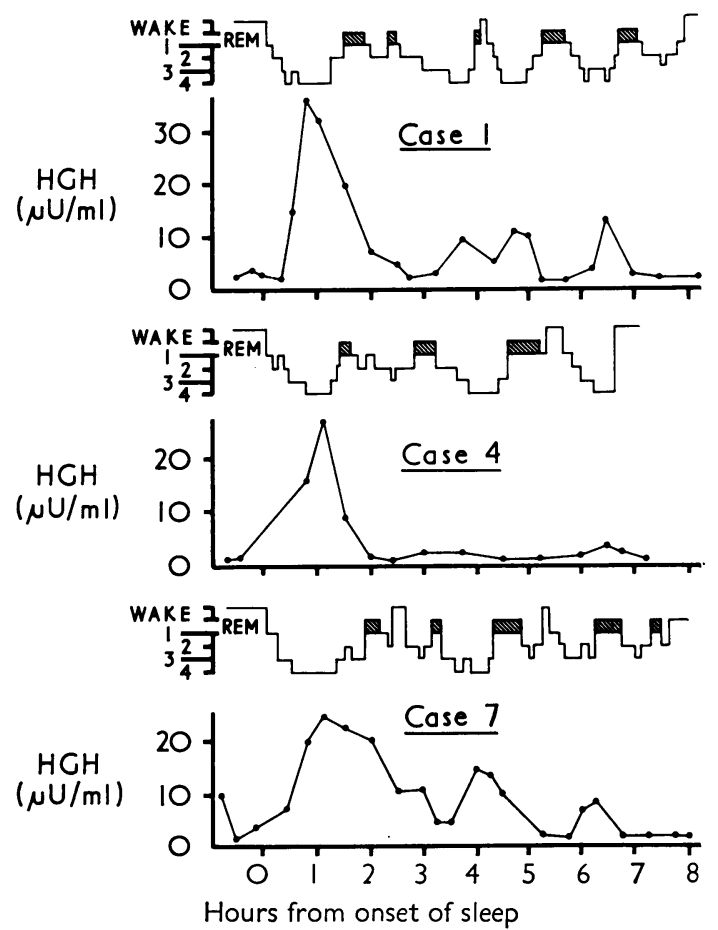

FIG. 1.-Representative patterns of growth hormone release during EEG-monitored sleep in 2 children with constitutional short stature (Cases 1 and 4) and 1 child with chronic asthma (Case 7). Sleep histogram stages: W, wake; stages 1 to 4 and REM by hatched bar. Stages 3 and 4 represent slow-wave sleep.

TABLE III

Comparison of plasma HGH responses to sleep, arginine infusion, and insulin-induced hypoglycaemia (peak plasma $H G H$ levels in $\mu U / m l$ )

\begin{tabular}{c|c|c|c}
\hline Case no. & Sleep & $\begin{array}{c}\text { Arginine } \\
\text { infusion }\end{array}$ & $\begin{array}{c}\text { Insulin-induced } \\
\text { hypoglycaemia }\end{array}$ \\
\hline 1 & $36 \cdot 8$ & $40 \cdot 8$ & $47 \cdot 6$ \\
2 & $26 \cdot 4$ & $25 \cdot 6$ & $32 \cdot 0$ \\
3 & $32 \cdot 2$ & $6 \cdot 4$ & $25 \cdot 6$ \\
4 & $27 \cdot 0$ & $8 \cdot 0$ & $13 \cdot 6$ \\
5 & $28 \cdot 8$ & $25 \cdot 6$ & $16 \cdot 0$ \\
6 & $14 \cdot 8$ & $7 \cdot 8$ & $26 \cdot 0$ \\
7 & $25 \cdot 2$ & $31 \cdot 0$ & $22 \cdot 2$ \\
8 & $18 \cdot 2$ & $28 \cdot 4$ & $17 \cdot 0$ \\
9 & $28 \cdot 4$ & $22 \cdot 4$ & $12 \cdot 0$ \\
10 & $1 \cdot 0$ & $1 \cdot 0$ & $1 \cdot 0$ \\
11 & $2 \cdot 0$ & $1 \cdot 0$ & $1 \cdot 0$ \\
12 & $4 \cdot 0$ & $20 \cdot 4$ & $7 \cdot 4$ \\
\hline
\end{tabular}


responses to pharmacological stimuli in these 2 cases. By contrast, the third case in this group (Case 12), whose peak HGH level during sleep was $4 \cdot 0 \mu \mathrm{U} / \mathrm{ml}$, showed a normal response to arginine $(20.4 \mu \mathrm{U} / \mathrm{ml})$ and a significant but blunted peak $\mathrm{HGH}$ response of $7.4 \mu \mathrm{U} / \mathrm{ml}$ to insulin-induced hypoglycaemia (Fig. 2). One year before this study

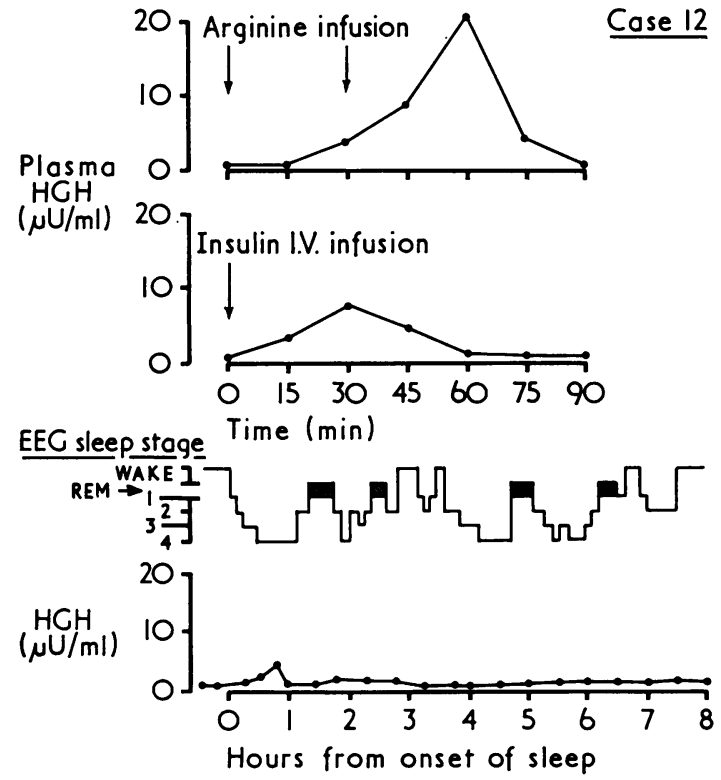

FIG. 2.-Growth hormone responses to arginine infusion, insulin-induced hypoglycaemia, and sleep in a 10.5-yearold boy suffering from short stature due to organic hypopituitarism. Normal growth hormone response to arginine contrasts with the blunted $H G H$ response to insulininduced hypoglycaemia and the lack of a significant rise in HGH during slow-wave sleep.

he had responded to insulin-induced hypoglycaemia with a peak plasma $\mathrm{HGH}$ level of $12 \cdot 0$ $\mu \mathrm{U} / \mathrm{ml}$. This boy, who was growing at a rate of $2.0 \mathrm{~cm} /$ year when these studies were performed, responded to a therapeutic trial of $\mathrm{HGH}$ with a height gain of $5.9 \mathrm{~cm}$ over the ensuing 6 months.

\section{Discussion}

HGH release during slow-wave sleep is a consistent and universal finding in healthy adults (Takahashi et al., 1968; Honda et al., 1969; Parker et al., 1969; Mace et al., 1970) and in normal prepubertal children over the age of 2 (Illig, Henrichs, and Stahl, 1971; Mace, Gotlin, and Beck, 1972; Underwood et al., 1971). Though HGH release is intimately related to the electrophysiological events of sleep, the exact nature of this association remains obscure. Persistent rises in plasma $\mathrm{HGH}$ in the newborn both during sleep and when awake suggest that sleep-induced $\mathrm{HGH}$ release is an acquired neuroendocrine rhythm (Illig et al., 1971; Shaywitz et al., 1971; Finkelstein et al., 1971; Vigneri and D'Agata, 1971). Once established in infancy, however, rhythmic sleep release of $\mathrm{HGH}$ is independent of factors known to influence $\mathrm{HGH}$ release during the waking hours. Acute changes in plasma substrates (Takahashi et al., 1968; Parker and Rossman, 1971), moderate exercise (Zir, Smith, and Parker, 1971), and adrenergic blocking agents (Lucke and Glick, 1971) do not appear to modify rhythmic sleep release of $\mathrm{HGH}$. In contrast with the lability of plasma $\mathrm{HGH}$ during the waking hours, the stability and reproducibility of nocturnal $\mathrm{HGH}$ release suggest that this component of $\mathrm{HGH}$ secretion may be concerned with the basic physiological role of $\mathrm{HGH}$ in promoting growth. If $\mathrm{HGH}$ secretion is the rate-limiting factor in a child's growth, then any impairment in $\mathrm{HGH}$ secretion resulting in growth retardation may well be reflected in the sleep-related HGH surge.

The clinical usefulness of measuring $\mathrm{HGH}$ release during sleep in growth retarded children is clearly shown by this study. Children, like adults, have significant rises in plasma $\mathrm{HGH}$ levels during slow-wave sleep, the peaks of which are comparable with the peak responses measured after the administration of arginine or insulin. With the exception of 1 patient, the peak plasma $\mathrm{HGH}$ level measured during sleep occurred within 2 hours of the onset of sleep and was associated with the first entry into slow-wave sleep. Re-entry into slow-wave sleep during subsequent sleep cycles was associated with rhythmic $\mathrm{HGH}$ release in most of the children who were not HGH deficient; however, the magnitude, duration, and frequency of these secondary peaks were quite variable (Fig. 1). Since $\mathrm{HGH}$ secretion rate is maximal during sleep (Alford, Baker, and Burger, 1971), it is probable that these secondary peaks contribute significantly to the overall daily production rate of $\mathrm{HGH}$.

The mean peak plasma $\mathrm{HGH}$ during sleep in the 9 children who were not $\mathrm{HGH}$ deficient was $26 \cdot 4 \pm 2 \cdot 2$ and in the $3 \mathrm{HGH}$-deficient children $2 \cdot 8 \mu \mathrm{U} / \mathrm{ml}$. Though we do not have a normal control group of prepubertal children with which to compare, it is interesting that the mean peak HGH level in the 9 children not $\mathrm{HGH}$ deficient is only slightly less than the mean peak plasma $\mathrm{HGH}$ level of $32 \cdot 8 \pm 4 \cdot 0 \mu \mathrm{U} / \mathrm{ml}$ we have previously reported in 12 normal young adults studied under similar conditions (Eastman, Mitchell, and Lazarus, 1971). Underwood et al. (1971), usine continuous 
EEG monitoring of the first 2 hours of sleep, reported a mean peak $\mathrm{HGH}$ level of $10.2 \mathrm{ng} / \mathrm{ml}$ in 16 normal children, while Mace et al. (1972) reported a mean peak of $17 \cdot 7 \mathrm{ng} / \mathrm{ml}$ in 46 normal children sampled 90 minutes after the onset of sleep.

Confirmation of $\mathrm{HGH}$ deficiency in the clinically suspect patient is usually obtained by measurement of plasma HGH levels after the application of a provocative pharmacological stimulus. The interpretation of $\mathrm{HGH}$ response to provocative stimulation tests is often difficult because of the high incidence of blunted or disparate responses observed (Youlton, Kaplan, and Grumbach, 1969; Raiti and Blizzard, 1970). There has been considerable speculation as to whether a blunted response to a single stimulus or a disparate response to two or more stimuli reflects either a spurious result or individual variation in the sensitivity of the hypothalamus to the stimulus employed or a state of partial HGH deficiency (Youlton et al., 1969). The results of the present study indicate that measurement of $\mathrm{HGH}$ release during sleep may also help to resolve this problem. In our study, 2 children (Cases 3 and 4) showed blunted $\mathrm{HGH}$ responses to arginine, but had normal HGH responses to insulin-induced hypoglycaemia. 1 of these children had shown a blunted HGH response $(10 \cdot 0 \mu \mathrm{U} / \mathrm{ml})$ to insulin-induced hypoglycaemia during a previous test. On the basis of physical signs, other pituitary function studies, and subsequent growth performance, it is highly unlikely that either of these 2 boys is suffering from partiai hypopituitarism. Using the magnitude of the sleep HGH peak as the sole criterion of normality of $\mathrm{HGH}$ secretion, there was a clear distinction between these 2 children and the HGH-deficient children. The value of the sleep peak in discriminating between normal children and those with partial HGH deficiency, as defined by Tanner et al. (1971), requires the study of a much larger series than presented here.

The intriguing question of whether a child may be capable of producing normal levels of $\mathrm{HGH}$ in response to provocative pharmacological stimuli, but be incapable of producing normal quantities of HGH during the normal course of life, has been raised recently by Tanner et al. (1971). They reported a patient who responded normally to both insulin and Bovril stimulation, but grew at a rate of $7.4 \mathrm{~cm} /$ year in response to $\mathrm{HGH}$ therapy as opposed to $3.7 \mathrm{~cm} /$ year the preceding year. It appears that 1 of our patients (Case 12) falls into this category. This boy responded normally to arginine with a peak plasma HGH level of $20 \cdot 4 \mu \mathrm{U} /$ $\mathrm{ml}$, but had a blunted $\mathrm{HGH}$ response of $7 \cdot 4 \mu \mathrm{U} / \mathrm{ml}$ to insulin-induced hypoglycaemia. His peak plasma HGH level during EEG-adjudged normal sleep was $4.0 \mu \mathrm{U} / \mathrm{ml}$. The dramatic acceleration in growth after the introduction of HGH therapy provided unequivocal evidence that growth retardation was due to $\mathrm{HGH}$ deficiency. Thus, it is suggested that growth retardation in this boy resulted from impairment of physiological HGH secretion occurring in association with partial preservation of responsiveness to provocative pharmacological stimuli. As $\mathrm{HGH}$ secretion is regulated by multiple independent pathways (Glick, 1969), it follows that functional or anatomical disturbances in the CNS may selectively involve one or more of these pathways while the others remain intact.

It is concluded from these studies that measurement of sleep-induced $\mathrm{HGH}$ release is a precise and sensitive index of physiological HGH secretion and is a valuable diagnostic tool in the investigation of children of short stature.

This work was performed while C.J.E. was in receipt of a Research Fellowship of the Asthma Foundation of N.S.W. and was supported in part by the National Health and Medical Research Council of Australia. We thank Dr. J. H. Casey for allowing us to study patients and for assistance in carrying out this study, and R. P. Mitchell, R. Comerford, and D. Melley for their technical assistance.

\section{REFERENCES}

Alford, F. P., Baker, H. W. G., and Burger, H. G. (1971). Twentyfour hour integrated plasma concentration and true secretion rate of human growth hormone. Proceedings of the 14th Annual Meeting of the Endocrine Society of Australia, 14, 39.

Eastman, C. J., and Lazarus, L. (1971). Comparison of growth hormone secretion during sleep and provocative tests of growth hormone release. Proceedings of the Second Internationl Symposium on Growth Hormone. Excerpta Medica International Congress Series, No. 236, p. 54. Ed. by A. Pecile and E. E. Muller. Excerpta Medica, Amsterdam.

Eastman, C. J., Mitchell, R. P., and Lazarus, L. (1971). Growth hormone secretion during sleep: studies of sleep induced growth hormone secretion in normal adults, acromegaly hypopituitarism and steroid induced growth retardation. Proceedings of the 14th Annual Meeting of the Endocrine Society of Australia, 14, 36.

Finkelstein, J. W., Anders, T. F., Sachar, E. J., Roffwarg, H. P., and Hellman, L. D. (1971). Behavioural state, sleep stage, and growth hormone levels in human infants. Fournal of Clinical Endocrinology and Metabolism, 32, 368.

Glick, S. M. (1969). Regulation of growth hormone secretion. In Frontiers in Neuroendocrinology, p. 141. Ed. by L. Martini and W. F. Ganong. Oxford University Press, London.

Hoffman, W. S. (1937). A rapid photoelectric method for the determination of glucose in blood and urine. fournal of Biological Chemistry, $120,51$.

Honda, Y., Takahashi, K., Takahashi, S., Azumi, K., Irie, M., Sakuma, M., Tsushima, T., and Shizume, K. (1969). Growth hormone secretion during nocturnal sleep in normal subjects. fournal of Clinical Endocrinology and Metabolism, 29, 20.

Illig, R., Henrichs, I., and Stahl, M. (1971). Growth hormone release during slow-wave sleep in 38 children. Proceedings of the Second International Symposium on Growth Hormone. Excerpta Medica International Congress Series, No. 236, p. 54. Ed. by A. Pecile and E. E. Muller. Excerpta Medica, Amsterdam. 
Lucke, C., and Glick, S. M. (1971). Experimental modification of the sleep-induced peak of growth hormone secretion. Fournal of Clinical Endocrinology and Metabolism, 32, 729.

Mace, J. W., Gotlin, R. W., and Beck, P. (1972). Sleep-related human growth hormone (HGH) release: a test of physiologic growth hormone secretion in children. Fournal of Clinical Endocrinology and Metabolism, 34, 339.

Mace, J. W., Gotlin, R. W., Sassin, J. F., Parker, D. C., and Rossman, L. G. (1970). Usefulness of post-sleep human growth hormone release as a test of physiologic growth hormone secretion. Fournal of Clinical Endocrinology and Metabolism, 31, 225.

Parker, D. C., and Rossman, L. G. (1971). Human growth hormone release in sleep: nonsuppression by acute hyperglycaemia. fournal of Clinical Endocrinology and Metabolism, 32, 65.

Parker, D. C., Sassin, J. F., Mace, J. W., Gotlin, R. W., and Rossman, L. G. (1969). Human growth hormone release during sleep: electroencephalographic correlation. fournal of Clinical Endocrinology and Metabolism, 29, 871.

Pennisi, F. (1968). A fast procedure for radioimmunoassay of $\mathrm{HGH}$ Fournal of Nuclear Biology and Medicine, 12, 137.

Penny, R., Blizzard, R. M., and Davis, W. T. (1969). Sequential arginine and insulin tolerance tests on the same day. Fournal of Clinical Endocrinology and Metabolism, 29, 1499.

Raiti, S., and Blizzard, R. M. (1970). Human growth hormone: current knowledge regarding its role in normal and abnormal metabolic states. Advances in Pediatrics, 17, 99.

Rechtschaffen, A., and Kales, A. (1968). (Editors) A Manual of Standardized Terminology, Techniques and Scoring System for Sleep Stages of Human Subjects. Public Health Service, U.S. Government Printing Office, Washington D.C.

Rodbard, D., Rayford, P. L., Cooper, J. A., and Ross, G. T. (1968). Statistical quality control of radioimmunoassays. Fournal of Clinical Endocrinology and Metabolism, 28, 1412.

Sassin, J. F., Parker, D. C., Johnson, L. C., Rossman, L. G., Mace, J. W., and Gotlin, R. W. (1969). Effect of slow wave sleep deprivation on human growth hormone release in sleep. Life Sciences, 8, Part 1, 1299.

Shaywitz, B. A., Finkelstein, J., Hellman, L., and Weitzman, E. D. (1971). Growth hormone in newborn infants during sleepwake periods. Pediatrics, 48, 103.

Takahashi, Y., Kipnis, D. M., and Daughaday, W. H. (1968). Growth hormone secretion during sleep. fournal of Clinical Investigation, 47, 2079.

Tanner, J. M., Whitehouse, R. H., Hughes, P. C. R., and Vince, F. P. (1971). Effect of human growth hormone treatment for 1 to 7 years on growth of 100 children, with $g$. wth. hormone deficiency, low birthweight, inherited smainess, Turner's syndrome, and other complaints. Archives of Disease in Childhood, 46, 745.

Underwood, L. E., Azumi, K., Voina, S. J., and Van Wyk, J. J. (1971). Growth hormone levels during sleep in normal and growth hormone deficient children. Pediatrics, 48, 946.

Vanderlaan, W. P., Parker, D. C., Rossman, L. G., and Vanderlaan, E. F. (1970). Implications of growth hormone release in sleev. Metabolism, 19, 891.

Vigneri, R., and D'Agata, R. (1971). Growth hormone release during the first year of life in relation to sleep-wake periods. Fournal of Clinical Endocrinology and Metabolism, 33, 561.

Youlton, R., Kaplan, S. L., and Grumbach, M. M. (1969). Growth and growth hormone. IV. Limitations of the growth hormone response to insulin and arginine and of the immunoreactive insulin response to arginine in the assessment of growth hormone deficiency in children. Pediatrics, 43, 989.

Zir, L. M., Smith, R. A., and Parker, D. C. (1971). Human growth hormone release in sleep: effect of daytime exercise. Fournal of Clinical Endocrinology and Metabolism, 32, 662.

Correspondence to Dr. C. J. Eastman, The Garvan Institute of Medical Research, St. Vincent's Hospital, Sydney 2010, N.S.W., Australia. 